\title{
Review of the marine environmental impact assessment reports regarding offshore wind farm
}

\author{
Hyun-Taik Oh*, Younjin Chung, Gaeun Jeon, Jeongmin Shim \\ Marine Environmental Impact Assessment Center, National Institute of Fisheries Science, Busan 46083, Korea
}

\begin{abstract}
The energy production of offshore wind farms plays an important role in expanding renewable energy. However, the development of offshore wind farms faces many challenges due to its incompatibility with marine environments and its social acceptability among the local community. In this study, we reviewed the marine environmental impact assessment status of offshore wind farm development projects for 2012-2019 in South Korea. A total of nine projects were selected for this study, all of which experienced considerable conflict with local fisheries resources. To appropriately respond to the underlying challenges faced by offshore wind farm development and in order to better support decision-making for future impact assessment, our findings identified: i) a need for adequate preliminary investigation and technical examination of fisheries resources; ii) a need to assess and estimate the impact of underwater noise, vibration, and electromagnetic waves on fisheries resources during wind farm construction and operation; and iii) a need for a bottom-up approach that allows for communication with local stakeholders and policy-makers to guarantee the local acceptability of the development.

Keywords: Offshore wind farm, Marine environmental impact assessment (MEIS), Fisheries resources, Renewable energy, Marine ecosystems
\end{abstract}

\section{Introduction}

According to the 'Renewable Energy Plan 3020' (Kim et al., 2020), the South Korean government plans to increase the production of renewable energy (e.g., wind and solar energy) to $20 \%$ of the overall energy production by 2030 . Offshore wind farms are an important renewable energy source, and they involve securing large farm sites and achieving mass production of high-density energy by utilizing consistent sea wind speed and direction (Kyong et al., 2003; Park \& Kim, 2019). With this new alternative to onshore wind farms, the Korean government projects the capacity of offshore wind energy to reach 12 GW by 2030, which is roughly half of the total renewable energy production goal. Despite many advantages, the development of offshore wind farms presents many challenges, particularly with respect to their impact on marine environments and ecosystems.

There have been many studies and regulations guiding marine environmental impact assessments needed for diverse devel-

Received: Aug 2, 2021 Revised: Sep 14, 2021 Accepted: Sep 29, 2021

${ }^{*}$ Corresponding author: Hyun-Taik Oh

Marine Environmental Impact Assessment Center, National Institute of Fisheries Science, Busan 46083, Korea

Tel: +82-51-720-2962, E-mail: ohtek@korea.kr

This is an Open Access article distributed under the terms of the Creative Commons Attribution Non-Commercial License (http://creativecommons.org/licenses/by$\mathrm{nc} / 4.0 /$ ) which permits unrestricted non-commercial use, distribution, and reproduction in any medium, provided the original work is properly cited.

Copyright $\odot 2021$ The Korean Society of Fisheries and Aquatic Science 
opment projects that utilize sea areas. However, it has been difficult to promote the development of offshore wind farms given its many challenges, including the low acceptability of local fishery operators, duplicated licensing pathways through the Ministry of Oceans and Fisheries and the Ministry of Environment, and the variable economic efficiency of wind conditions (Kim et al., 2012). To address these challenges, studies have been conducted on the assessment criteria used for measuring the impact of developing offshore wind farms on marine ecosystem and fisheries resources (Maeng et al., 2013) and locating offshore wind farms at optimal farm sites (Kim et al., 2009; Kim et al., 2016). These studies suggest the need for additional assessments on the extent of fishery damage and the impact of wind farm development on marine protected areas and species. Some of the core assessment items, such as wind conditions, underwater noise, and fisheries resources, have also been prioritized for the development of offshore wind farms (Lee et al., 2016).

However, there has been insufficient scientific investigation, lack of impact evaluation, and ongoing management of offshore wind farms due to the lack of understanding of marine fisheries resources. Assessments have mostly relied on theoretical solutions for environmental damage reduction without evaluating the validity of farm locations. Furthermore, there are no specific legal criteria for addressing the damage to marine ecosystems and fisheries resources from underwater noise, vibration, and electromagnetic waves. This increases the risk of conflicts of interest among all relevant stakeholders, including wind farm developers and fisheries operators. Moreover, by applying a topdown approach to the assessment process (an approach used by the government for the development of electric stations), offshore wind farms were developed without consulting the local fishery operators and with limited communication with local communities. The development of farm sites has reduced fishing areas, and this has exacerbated the conflicts with local fishers (Park \& Kim, 2016). To mitigate such conflict, it is important to foster a mutual understanding involving all stakeholders prior to undertaking any wind farm development (Lee et al., 2011).

In this study, we examined the status of marine environmental impact assessments for the development of offshore wind farms in South Korea, identified key problems arising from offshore wind farm development, and offered solutions that can best support both marine conservation and utilization while producing offshore wind power. Using assessment data for Korea's wind farm projects, we have addressed the follow- ing issues: 1) understanding of marine fisheries resources; 2) estimation of the impact of underwater noise, vibration, and electromagnetic waves on fisheries resources; and 3) resolution of conflicts of interest with all relevant stakeholders, including local fishery operators.

\section{Materials and Method}

\section{Materials-Marine Environmental Impact Statements (MEISs)}

Prior to obtaining a development license, marine project agencies utilizing sea areas are required to assess the marine environmental impacts and overall viability of their projects. A Marine Environmental Impact Statement (MEIS) is required for the assessment and licensing approval process of the Ministry of Oceans and Fisheries (Kim et al., 2009). This system is designed to assess marine environment impacts in line with the system used by the Ministry of Environment for assessing environmental impacts (Lee et al., 2011). Prior to 2020, if the development scale exceeded a certain size (e.g., wind power capacity $\geq 100 \mathrm{MW}$ for offshore wind farm projects), a marine infrastructure project was required to undertake a marine environmental impact assessment by the Ministry of Oceans and Fisheries and an environmental impact assessment by the Ministry of Environment.

The Marine Environment Management Act in South Korea, defines two main types of MEIS requirements based on the project scale, i.e., large and small. For developing offshore wind farms, project scale is based on wind power capacity, with large projects having the capacity to produce greater than or equal to 100 MW. Large projects were required to obtain duplicate approvals from both the Ministry of Oceans and Fisheries and the Ministry of Environment. In 2020, new project scale criteria for offshore wind farm projects were introduced. According to the new criteria, a project is large or macro (its MEIS is defined as 'MEIS-MA' in this study) if the total wind power capacity to develop is greater than or equal to $50 \mathrm{MW}$ and less than $100 \mathrm{MW}$. Meanwhile, small projects with a capacity less than $50 \mathrm{MW}$ are further divided into two types: general (defined as 'MEIS-GE' in this study; the total size of development site is greater than or equal to 3,000 $\mathrm{m}^{2}$ ) and simplified or micro (defined as 'MEISMI' in this study; the size is less than $3,000 \mathrm{~m}^{2}$ ). Since 2020, a project with a total wind power capacity greater than or equal to $100 \mathrm{MW}$ is required to obtain a license only from the Ministry of Environment.

All MEISs submitted for the development of offshore wind farms between 2012 and 2019 in South Korea were collected for 
this study. Among these, only feasible MEISs were considered and the environmental impact associated with the development of the project was assessed. For preparing offshore wind farm development, the infrastructure project agencies were also required to install meteorological towers at their development site to investigate and document the viability of the wind power generation potential and the economic efficiency of the wind resource. This assessment required a MEIS-MI to examine the project viability, and such MEIS-MIs were excluded from this study as they were not used to assess the marine environmental impact on fisheries resources. Additionally, we excluded MEISs if the project did not account for the impact caused by the development of floating farms or utilization of reclaimed sea areas on marine ecosystems and fisheries resources. We also excluded MEISs if the project was canceled.

\section{Methods-Analysis of assessment information used for Ma- rine Environmental Impact Statements (MEISs)}

Among the natural environment and socio-economic factors, those concerned with the marine environment were selected for marine environmental impact assessment (Kim et al., 2012). The basic factors for small projects, especially general projects, are classified into nine assessment categories: marine physics, marine chemistry, marine sediments, marine geography and geology, pelagic ecosystems, benthic ecosystems, protected areas and species, fisheries resources, and landscape and recre- ation. There are five additional assessment categories for large or macro projects; weather, fish eggs and larvae, marine plants, intertidal animals, and marine industries. The MEIS-MA for large projects is required to describe the impact analysis for the assessment items in each of the 14 categories, while the basic nine categories are applied to MEIS-GE and MEIS-MI for small projects (circled in Table 1). Among the circled categories and items in Table 1, the double circled ones were the main items assessed when proposing offshore wind farms.

The impact assessment includes the understanding of current environmental conditions, estimation of potential impact, proposal of an impact reduction plan, and a post monitoring plan. The potential impacts can be estimated by modeling marine mechanics such as sea flow and maximum diffusion of suspended particles, combined with an informed literature review and field observations. To assess the adequacy of securing the development site for offshore wind farms, it is necessary to measure the amount of energy production and the rate of farm utilization based on weather resources. Weather information includes the monthly and yearly datasets of wind direction and velocity for the previous 10 years, which have been applied to only assess the marine environmental impact of large projects (Kim et al., 2012). There are some other factors that are critical for the development of offshore wind farms but are not categorized for assessment. One of them is local acceptability, which has been considered only for large projects that have been

Table 1. Assessment categories and items for measuring marine environmental impact of large (macro) and small (general and micro) projects for utilizing offshore areas of South Korea

\begin{tabular}{|c|c|c|c|}
\hline Assessment category & Assessment item & Large project & General project \\
\hline Marine physics & Sea flow, tide, wave, water level, etc. & (C) & () \\
\hline Marine geography \& geology & Erosion, settlement, granularity, etc. & (C) & (2) \\
\hline Weather & Wind direction \& velocity, precipitation, etc. & $\bigcirc$ & - \\
\hline Marine chemistry & Suspended particles, water quality, etc. & $\bigcirc$ & (0) \\
\hline Marine sediments & Sediment resuspension, heavy metal, etc. & (2) & (2) \\
\hline Pelagic ecosystem & Phytoplankton, zooplankton, etc. & (2) & (2) \\
\hline Fish eggs \& larvae & Fish eggs, larvae, juveniles, etc. & (2) & - \\
\hline Benthic ecosystem & Phytobenthos, zoobenthos, etc. & (a) & (a) \\
\hline Fisheries resources & Fish, shellfish, aquaculture, etc. & (a) & (a) \\
\hline Marine plants & Seaweed, marine algae, etc. & $\bigcirc$ & - \\
\hline Intertidal animals & Rock animals, mud animals, etc. & $\bigcirc$ & - \\
\hline Protected areas \& species & Wetland, endangered species, etc. & (2) & (2) \\
\hline Landscape \& recreation & Landscape, visual impact (scenic amenity), landmark, etc. & $\bigcirc$ & $\bigcirc$ \\
\hline Marine industry & Fishery, shipping lane, fishing port, shipping harbor, cultural factors, etc. & $\bigcirc$ & - \\
\hline
\end{tabular}

$\bigcirc$, marks the basic categories and items assessed for the project; $\bigcirc$, marks the main or key categories and items among the basic ones assessed for the project. 
compelled to hold project information sessions for local stakeholders and submit project information to the public as part of the assessment. Information on underwater noise, vibration, and electromagnetic waves has also not been included in the assessment (Lee et al., 2016). Therefore, they have been further requested to provide supplementary impact statements including analysis of the additional items, which can significantly affect marine ecosystems and fisheries resources.

Based on the assessment categories and items in Table 1, we examined the assessment status of the MEISs included in this study. We have presented our findings not only to show how their marine environmental impacts are currently assessed, but also to consider implications for the future application of MEISs in developing offshore wind farms. Furthermore, we have identified key issues concerning the current assessment and elucidated the gaps in promoting offshore wind farm development for future assessments, with the aim of achieving the best-practice production of renewable energy in South Korea.

\section{Results and Discussion}

Between 2012 and 2019, there were a total of 81 preliminary MEIS-MIs for installing meteorological towers and investigating the development viability of offshore wind farms (Fig. 1).
$87 \%$ of the MEIS-MIs were submitted for farm projects in Jeonnam province (57 MEIS-MIs, 70\%) and Jeonbuk province (14 MEIS-MIs, 17\%), which were surrounded by the southwestern sea in South Korea. Most of the MEIS-MIs (81\%) were submitted in 2018 (19 MEIS-MIs, 23\%) and 2019 (47 MEIS-MIs, $58 \%)$. Although all 81 preliminary MEIS-MIs were excluded in this study, the development of offshore wind farms has been a growth industry in South Korea since 2018.

The farm projects approved for their viability are then able to submit their MEISs for farm development and construction. A total of 15 MEIS-GEs between 2012 and 2019 (Fig. 1) were examined for this study. Of those, nine MEIS-GEs completed their examination and four were still in the consultation phase, while two were canceled. Another four MEIS-GEs were excluded because the projects were small scale and their floating wind power generators or development sites had been reclaimed for salt farms. These projects were regarded as having no impact on marine ecosystems and fisheries resources. Thus, the final nine MEIS-GEs in Fig. 2 were selected for this study.

Four projects were proposed for the development of offshore wind farms around Jeju Island (J1-J4, Fig. 2 and Table 2), while five projects were proposed for farm development in the southwestern sea area of Jeonnam and Jeonbuk provinces (Y1Y5, Fig. 2 and Table 2). Among the projects around Jeju Island,

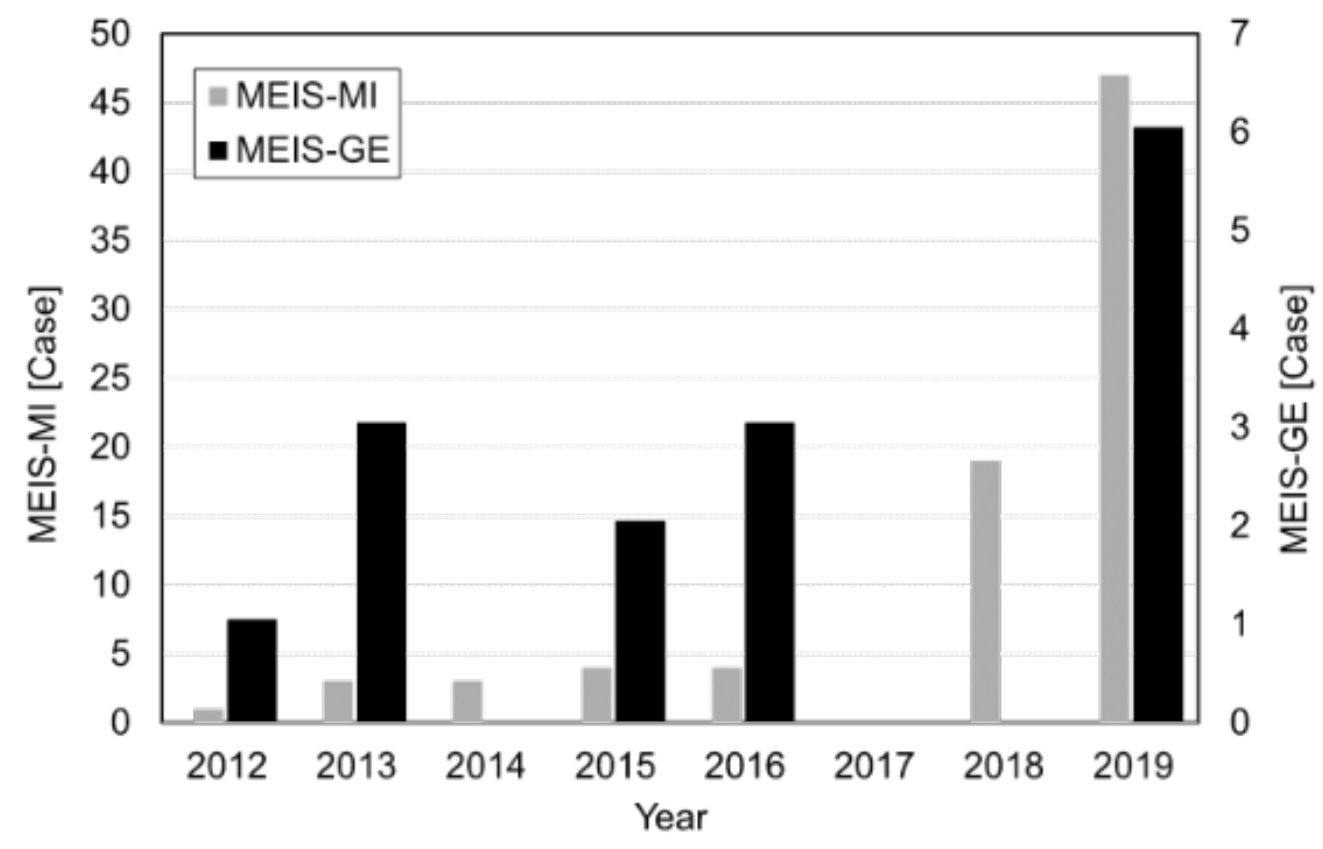

Fig. 1. Number of MEIS-MIs for collecting weather data and MEIS-GEs for construction submitted for offshore wind farm projects between 2012 and 2019 in South Korea. MEIS, Marine Environmental Impact Statement. 


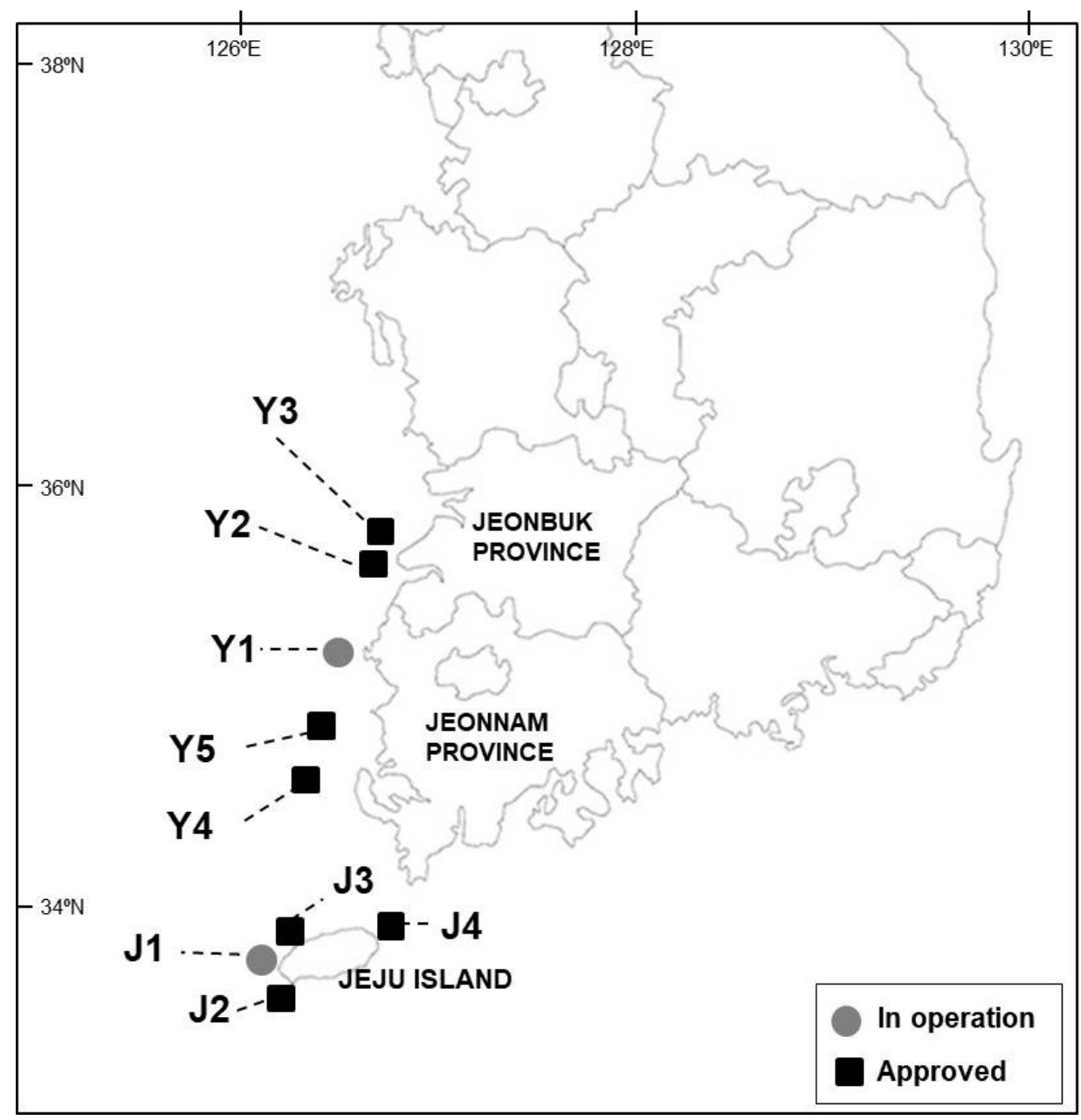

Fig. 2. Location of offshore wind farm projects for both Jeju Island and the Southwest Province in South Korea (in operation or approved).

the MEIS-GE of 'J1' was assessed and approved for development in 2012; the Tamra Wind Farm was completed in 2017, and it is now in operation. This project installed ten wind energy generators of $3 \mathrm{MW}$ each (30 MW in total) to produce approximately $85,000 \mathrm{MW}$ per year in order to meet the energy requirements for approximately 24,000 households on Jeju Island. The other three projects (J2, J3, and J4), with a total power capacity greater than or equal to $100 \mathrm{MW}$, were also assessed by the Ministry of Oceans and Fisheries; they are currently progressing through the assessment process required by the local authority of Jeju Island.

Among the projects in the southwestern sea area, only the Southwest Wind Farm (Y1) is in operation. The initial development phase of this project generated $60 \mathrm{MW}$, with approval to complete $400 \mathrm{MW}$ during the implementation phase. An additional $2 \mathrm{GW}$ will be produced during the distribution phase by achieving economic efficiencies and increased local uptake. The 'Y1' project is currently undertaking a change analysis of relevant assessment items and monitoring noise stress from the construction to estimate the potential impact of the farm operation on marine ecosystem and fisheries resources. In Jeonnam province, there was one MEIS-GE submitted for the large project 'Y5' (total power capacity $\geq 100 \mathrm{MW}$ ) before 2020 and assessed by both the Ministry of Oceans and Fisheries and the Ministry of Environment.

The wind farm projects in the two different areas followed different development patterns due to varying water depths and distances from the coastline. As shown in Fig. 3, the average 
Table 2. List of offshore wind farm projects in South Korea

\begin{tabular}{lllllll}
\hline ID & Name & Year & Cap $(\mathrm{MW})$ & Size $\left(\mathrm{m}^{2}\right)$ & WD $(\mathrm{m})$ & Dist $(\mathrm{km})$ \\
\hline J1 & Tamra & 2012 & $30(3 \mathrm{MW} \times 10)$ & 622,491 & $13-42$ & $0.4-1.3$ \\
J2 & Daejeong & $2013(2019)$ & $100(5-6 \mathrm{MW} \times 17-20)$ & $29,000,000$ & $25-60$ & $2.0-5.0$ \\
J3 & Hanlim & 2019 & $100(5.56 \mathrm{MW} \times 18)$ & $5,469,687$ & $13-49$ & $0.7-2.2$ \\
J4 & Handong-Pyeongdae & 2019 & $104.5(5.5 \mathrm{MW} \times 19)$ & $5,630,000$ & $21-63$ & $1.1-3.9$ \\
Y1 & Southwest & 2015 & $60(3 \mathrm{MW} \times 20)$ & $8,848,910$ & $9.0-10.5$ & $10.2-13.6$ \\
Y2 & Saemangeum & 2015 & $98.8(2.8 \mathrm{MW} \times 35)$ & 232,548 & $2.9-4.1$ & 0 (inside the coastline) \\
Y3 & Gunsan & 2016 & $68(3.2 \mathrm{MW} \times 17,2.0 \mathrm{MW} \times 7)$ & 202,840 & $0.3-7.6$ & $1.5-2.0$ \\
Y4 & Jeonnam & 2019 & $96(8 \mathrm{MW} \times 12)$ & 635,013 & $10-18$ & $8.6-14.3$ \\
Y5 & Yeonggwang-Nagwol & 2019 & $352.8(4.2 \mathrm{MW} \times 84)$ & $1,481,763$ & $15.3-17.2$ & $5.5-6.8$
\end{tabular}

ID, project ID; Name, project name; Year, year of MEIS submission; Cap, total power capacity; Size, area of development site; WD, water depth; Dist, distance of farm from coastal line; MEIS, Marine Environmental Impact Statement.

water depths for the projects in the southwestern sea areas were lower than those around Jeju Island, while the average distances from the coastal line for the projects in the southwestern sea area are more than for those around Jeju Island. Topographically, the water depth in the southwestern sea area is less than that in the southern sea area, where Jeju Island is located, while the water depths in both sea areas are much lower than in the eastern sea area of South Korea (Seo, 2008). Despite their shallower water, the wind velocities in the southern and southwestern areas are stable and adjacent to the big and centralized cities of South Korea (Kim et al., 2013).

As artificial structures of offshore wind farms affect marine ecosystems and fisheries resources, it has been recommended that wind farm development occur at least $5 \mathrm{~km}$ from the shore. However, the MEIS-GE data in this study showed that most of the farm sites were closer to the coastline (within $2 \mathrm{~km}$ ). Farms developed closer to coastlines were exposed to civil appeals and compensation litigation for local fisheries resources that experienced marine environment degradation. Even though some projects within $2 \mathrm{~km}$ were small-scale, the turbines installed on the sea surface impacted the visual amenity of the landscape. It is also expected that the amenity of local community lifestyles and fisheries resources would be impacted by atmospheric and underwater noise produced by the rotating blades. Thus, we analyzed the assessment status of the MEIS-GEs and examined the following issues in order to guide better impact assessment of marine ecosystems and fisheries resources for wind farm development.

\section{Understanding of marine fisheries resources}

In assessing marine physics, chemistry, and ecosystems, all the

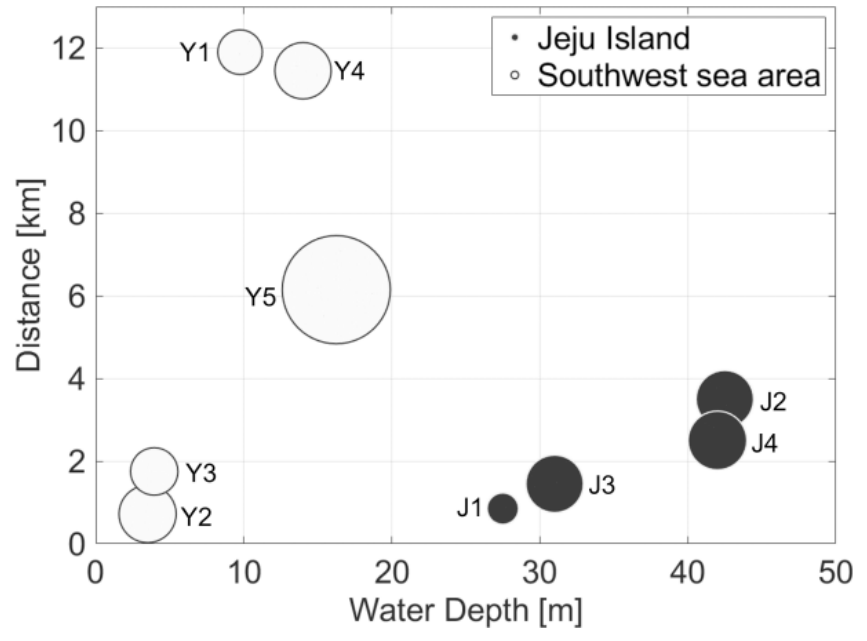

Fig. 3. Distribution of nine offshore wind farm projects in the southwestern sea area (black circles) and Jeju Island (white circles) according to water depth and distance from the coastline (the circle size indicates total wind power capacity).

MEISs in this study provided an inadequate understanding of marine fisheries resources with unreliable information about the relevant assessment items. The assessment methods were inconsistent, and they described only the current marine conditions without analyzing the impact of wind farm developments on marine ecosystems. In particular, the assessment of fisheries resources was not robust and lacked information about the fishing industry, fishing infrastructure, commercial operations, and primary species of fish. Information about the productivity of all local fishery resources was also insufficient for understanding the fishery conditions within the impact range of offshore 
wind farms.

For a better understanding of marine fisheries resources, it is essential to perform a preliminary investigation of the fishing industry, fishers, and statistics of local governments as well as the National Federation of Fisheries Cooperatives. There is also a need for technically examining the type of fisheries resource (e.g., gill net, trap, beam trawl, purse net, line trawl, stow net, and fishing farm) to obtain relevant information on the fishing method, equipment and operation prior to assessing fisheries resources. For each type of fisheries resource, it is necessary to assess the additional impact on fishery areas, net structure, collision incidence, and productivity. Owing to the high mobility of marine life, it is also necessary to select investigation points based on the information of fisheries resources rather than the depth of water. As most species of fish migrating to South Korea move within the range of $100-1,000 \mathrm{~km}$, it is not adequate to investigate the vertical distribution of fish, because it limits the assessment. Therefore, local fisheries resources should be assessed using field studies and literature surveys.

\section{Estimation of the impact of underwater noise, vibration, and electromagnetic wave}

To develop offshore wind farms, the impact of underwater noise, vibration, and electromagnetic waves on marine ecosystems should be assessed and estimated during both construction and operation. However, most of the projects, except Daejeong Wind Farm (J2) and the Southwest Wind Farm (Y1) in Fig. 2, provided unverified datasets and limited one-time monitoring data of underwater noise, vibration, and electromagnetic waves. Only the Southwest Wind Farm project assessed the impact of the turbine support jacket and showed that underwater noise above $210 \mathrm{~dB}$ could damage the marine environment within $20 \mathrm{~m}$ of the infrastructure. However, they arbitrarily calculated underwater noise $(62 \mathrm{~dB})$ by adding its difference from the air noise for reference $(26 \mathrm{~dB})$ and impedance $(36 \mathrm{~dB})$ (Dickens et al., 2007; Lim et al., 2010) instead of using a hydrophone owing to limited equipment and space.

There have been studies on thresholds for underwater noises harmful to marine mammals; for example, $140 \mathrm{~dB}$ re $1 \mathrm{uPa}$ for bottlenose dolphins (Southall et al., 2008); $155 \mathrm{~dB}$ re $1 \mathrm{uPa}$ for harbor porpoise (Southall et al., 2008); and $143 \mathrm{~dB}$ re $1 \mathrm{uPa}$ for minke whales (Bailey et al., 2010). The threshold for harbor porpoises decreases to as little as $90 \mathrm{~dB}$ when they are in a sensitive period, and they totally avoid the noise source (Sohn et al., 2015). An offshore wind farm can exceed these thresholds and disturb the ecological balance of marine mammals (Bailey et al., 2010). While not many studies have assessed the impact of underwater noise on marine organisms and fish in South Korea, there has been significant research on the bottlenose dolphins around Jeju Island. No official regulations or guidelines for underwater noise have been investigated, except for the one case study on the negative impacts of underwater noise on eel farms located near highway construction (Sohn et al., 2015). Studies on the damage criteria of underwater noise for marine life, which are a result of the development of offshore wind farms, have been conducted in the USA, Belgium, and the Netherlands, and through the United Nations (Brennan et al., 2014).

Most fish in the southwestern sea area of South Korea are demersal. Owing to their relatively low mobility, they can suffer from underwater noise and vibration due to the construction of offshore wind farms (Choi et al., 2014). It is inevitable for shellfish exposed on the sand to suffer from pile noise during farm construction and for fish around the coastal area to avoid the source of blade noise during wind farm operation (Table 3). Furthermore, electromagnetic waves that occur during the operation of wind farms are another damage factor that causes a change in the marine ecosystem with behavioral disturbances and unexpected migration. This requires further research on the impact of electromagnetic waves on marine ecosystems and fisheries resources for wind farm development.

\section{Resolution of conflicts of interest among all relevant stake- holders}

The projects in this study did not involve any public meetings to receive feedback about wind farm development from the local communities. Instead, a top-down approach was developed and used by the government for the approval of electric power stations and offshore wind farms. Since this approach undertook marine development without community consultation, it had limited communication with local people. Such farm development downsized fishing areas and damaged marine protected species. This has resulted in considerable conflicts of interest between all relevant stakeholders, including project developers, agencies, and local communities, especially for fisheries resources (Park \& Kim, 2016). For farm development, it is important to assess compatibility with the marine environment and its acceptability to the local community.

There is a need for further research on fishing losses caused by wind farm development. The application of restricted areas such as no-fishing areas during the development period is to 
Table 3. Possible impact of underwater noise on fishery resources: fish, shellfish, and seaweed

\begin{tabular}{|c|c|c|c|c|}
\hline & & Fish & Shellfish & Seaweed \\
\hline \multirow{4}{*}{$\begin{array}{l}\text { Pile noise } \\
\text { (construction) }\end{array}$} & Impact & (2) & 0 & • \\
\hline & Species & Paralichthys olivaceus & Venerupis philippinarum & - \\
\hline & Causes & Expose to sand & Expose to sand & - \\
\hline & Threshold & $120 \mathrm{~dB}(10-15 \mathrm{~Hz})$ & $100 \mathrm{~dB}(30 \mathrm{~Hz})$ & - \\
\hline \multirow{3}{*}{$\begin{array}{l}\text { Blade noise } \\
\text { (operation) }\end{array}$} & Impact & (2) & - & • \\
\hline & Causes & Away & - & - \\
\hline & Threshold & $120 \mathrm{~dB}(10-15 \mathrm{~Hz})$ & $100 \mathrm{~dB}(30 \mathrm{~Hz})$ & - \\
\hline
\end{tabular}

Impact indication: high, medium, and unknown impacts are denoted by a double circle, single circle, and dot, respectively; not applicable impacts are denoted by a dash.

secure the safety of shipping lanes and prevent the occurrence of accidents, such as collisions between vessels (Son et al., 2019). In South Korea, there have been no criteria for safe distances. However, recommendations for applying the restricted area within $500 \mathrm{~m}$ from the farm refer to Article 60 of the United Nations Convention on the Law of the Sea (UNCLS). The no-fishing area recommended by the UNCLS is a fixed rectangle located $500 \mathrm{~m}$ away from all the boundary turbines of offshore wind farms, during both construction and operation. In Europe, this area is applied as a $500 \mathrm{~m}$ radius from each turbiner during construction and $50 \mathrm{~m}$ from each winder during operation. Consequently, the no-fishing area defined by the UNCLS has been claimed to be excessive for local stakeholders, including fishers (Hooper et al., 2015).

If the restriction criteria used in Europe is applied here, the total no-fishing area during operation for the 'Southwest' farm ('Y1') becomes only $1.78 \%$ of the total wind farm area (Table 4). The total no-fishing area during operation can be $2.37 \mathrm{~m}^{2}$, which is $30.9 \%$ of the total farm area, if it applies a $100 \mathrm{~m}$ radius only for direct utilization. Even within this restricted area, it is still possible to engage in fishing activities that do not inflict physical impacts on the seabed. Therefore, the complaints on downsizing fishing areas by the development of offshore wind farms can be reduced by adopting the European restriction criteria. For this reason, the 'Southwest' farm project utilizing the southwestern sea area is planning to allow vessel traffic under 10 tons and fishing activities $50 \mathrm{~m}$ away from the farm.

It is also important to adopt a bottom-up approach over the top-down approach for policymaking to guarantee the local acceptability of the development of offshore wind farms. For an appropriate assessment, the following methods were discussed in this study:

1) Improvement of the assessment system: It is essential to
Table 4. Size of the no-fishing area during operation for the 'Southwest' farm (' $Y 1$ ' in Fig. 2) when adopting the restriction criteria used in Europe (UK and Denmark)

\begin{tabular}{llll}
\hline & Offshore wind farm & $\begin{array}{c}\text { No-fishing area } \\
(100 \mathrm{~m})\end{array}$ & $\begin{array}{c}\text { No-fishing area } \\
(50 \mathrm{~m})\end{array}$ \\
\hline Size $\left(\mathrm{km}^{2}\right)$ & 8.848 & 2.37 & 0.16 \\
Ratio $(\%)$ & 100 & 30.9 & 1.78 \\
\hline
\end{tabular}

define the project scale of offshore wind farms for assessing the marine environmental impact. Regardless of the project scale (large or small), assessment needs to include local community feedback and agreement in order to be approved by the Ministry of Oceans and Fisheries as well as the Ministry of Environment. The system, especially for small projects, can then be improved by requesting project information sessions for local stakeholders and involving local fishery operators in the development process.

2) Enforcement of the local agreement process: As two values of marine development and conservation are often in conflict, it is essential to run a consultative committee for local agreements. The current assessment system for the extraction of marine aggregates requires the binding of agreed documents with local stakeholders. Therefore, a documented agreement with local fisheries operators is also required for marine environmental impact assessment to implement the development of offshore wind farms.

3) Enhancement of local acceptability: There is a need for scientific investigation of fishery losses in terms of damage area caused by the development of offshore wind farms. Compensation for fishery losses should be evalu- 
ated by estimating the annual average sale price for each type of fishery resource, the cost of fishery operations, and the rate of return cost, based on the amount of fisheries resources and the reduction ratio of fishery production. This comprehensive approach for the acceptability assessment should include information on licensed fisheries resources, local government statistics, and involve the National Federation of Fisheries Cooperatives, as well as input from fisheries operators through a consultation program.

A local consultative committee should be organized with all relevant stakeholders and marine environmental experts. To better mitigate conflict, the committee should run consultations from the early stages of project development and involve local stakeholders in a cooperative process. It is also desirable to include seasonal monitoring of marine environments, fisheries resources, and marine protected species during development and operation. By applying the above methods, wind farm projects can better reflect local feedback and resolve conflicts such as a reduction in fishing areas. An improved assessment system with additional consideration of marine ecosystems and fisheries resources can help to promote the development of offshore wind farms and increase renewable energy production.

\section{Conclusion}

In this study, we examined the status of marine environmental impact assessments proposed for developing offshore wind farms in South Korea. Using the assessment data of a total of nine projects, we identified key problems arising from farm development in relation to its impact on marine ecosystems and fisheries resources. Among these projects, only Daejeong Wind Farm near Jeju Island and the Southwest Wind Farm in the southwestern sea area provided verified datasets and sufficient monitoring data for underwater noise, vibration, and electromagnetic waves. For most of the farms, there was a lack of impact information collected for marine ecosystems, fisheries resources, and protected species, where a conflict occurred with the local fisheries. To address the underlying problems, we provided guidelines to better understand marine fisheries resources using scientific investigation and estimated the impact of underwater noise, vibration, and electromagnetic waves caused by development and operation of wind farms on fisheries resources. We also suggested the application of a bottom-up approach to resolve conflicts between project developers and fishery operators by involving them in the co-development process. Additionally, we discussed methods for a bottom-up approach while elucidating the need to improve the assessment system, enforce local agreement processes, and improve local acceptability. The suggestions in this study provide helpful guidance for effectively promoting the development of offshore wind farms and efficiently increasing renewable energy production for meeting the goals of the South Korea's 'Renewable Energy Plan 3020'.

\section{Competing interests}

No potential conflict of interest relevant to this article was reported.

\section{Funding sources}

This study was supported by the National Fisheries Institute monitoring project of aquaculture environment (R2021055).

\section{Acknowledgements}

Not applicable.

\section{Availability of data and materials}

Upon reasonable request, the datasets of this study can be available from the corresponding author.

\section{Ethics approval and consent to participate}

This article does not require IRB/IACUC approval because there are no human and animal participants.

\section{ORCID}

Hyun-Taik Oh https://orcid.org/0000-0001-7239-5943

Younjin Chung

Gaeun Jeon https://orcid.org/0000-0002-2055-6845

Jeongmin Shim https://orcid.org/0000-0002-3030-5556 https://orcid.org/0000-0001-5680-6415

\section{References}

Bailey H, Senior B, Simmons D, Rusin J, Picken G, Thompson $\mathrm{PM}$. Assessing underwater noise levels during pile-driving at an offshore windfarm and its potential effects on marine mammals. Mar Pollut Bull. 2010;60:888-97.

Brennan J, Fitzsimmons C, Gray T, Raggatt L. EU marine strategy framework directive (MSFD) and marine spatial planning (MSP): which is the more dominant and practicable contributor to maritime policy in the UK? Mar Policy. 
2014;43:359-66.

Choi Y, Lee HH, Oh JK. Distribution of fishes around the offshore wind farm at the southern part of Yellow Sea by trawl net. Korean J Ichthyol. 2014;26:222-9.

Dickens P, Smith J, Wolfe J. Improved precision in measurements of acoustic impedance spectra using resonance-free calibration loads and controlled error distribution. J Acoust Soc Am. 2007;121:1471-81.

Hooper T, Ashley M, Austen M. Perceptions of fishers and developers on the co-location of offshore wind farms and decapod fisheries in the UK. Mar Policy. 2015;61:16-22.

Kim GY, Lee DI, Jeon KA, Eom KH, Woo YS. Diagnosis for review of statement and system improvement of consultation on the coastal area utilization in Korea. Korean Soc Mar Environ Saf. 2009;15:345-54.

Kim GY, Lee DI, Jeon KA, Eom KH, Yu J. Improvement for marine environmental impact assessment on the development of offshore wind power. J Environ Impact Assess. 2012;21:1-13.

Kim JH, Nam J, Yoo SH. Public acceptance of a large-scale offshore wind power project in South Korea. Mar Policy. 2020;120:104141.

Kim JY, Kang KS, Oh KY, Lee JS, Ryu MS. Assessment of possible resources and selection of preparatory sites for offshore wind farm around Korean peninsula. New Renew Energy. 2009;5:39-48.

Kim KY, Jeong SJ, Lee SJ. Construction technology roadmapping for port offshore wind farm. J Digital Converg. 2013;11:137-48.

Kim T, Park JI, Maeng J. Offshore wind farm site selection study around Jeju Island, South Korea. Renew Energy. 2016;94:619-28.

Kyong NH, Yoon JE, Jang MS, Jang DS. An assessment of offshore wind energy resources around Korean Peninsula. J Korean Sol Energy Soc. 2003;23:35-41.

Lee DI, Kim GY, Jeon KA, Eom KH, Yu J, Kim YT, et al. An application status and consideration of system improvement on the sea area utilization conference and impact assessment. J Korean Soc Mar Environ Energy. 2011;14:239-48.

Lee DI, Kim GY, Tac DH, Yi YM, Choi JH, Kim HJ, et al. Diagnosis of scoping and type of review on the marine environmental impact assessment for ocean energy development project. J Korean Soc Mar Environ Energy. 2015;18:179-88.

Lim DK, Shin YC, Jun YB. A study on the establishment of management criteria for underwater noise. Explos Blasting.
2010;28:119-32.

Maeng JH, Cho BJ, Lim OJ, Seo J. A study on the environmental impact of offshore wind farms through monitoring case in overseas country. J Korean Soc Mar Environ Energy. 2013;16:276-89.

Park J, Kim B. An analysis of South Korea's energy transition policy with regards to offshore wind power development. Renew Sustain Energy Rev. 2019;109:71-84.

Park JI, Kim T. Institutional improvement measures for environmental assessment in the pursuit of eco-friendly ocean renewable energy development in South Korea. Renew Sustain Energy Rev. 2016;58:526-36.

Seo SN. Digital 30sec gridded bathymetric data of Korea marginal seas - KorBathy30s. J Korean Soc Coastal Ocean Eng. 2008;20:110-20.

Sohn H, An DH, Kim HW. A study on the legal frame to manage anthropogenic underwater noise for marine mammal protection in Korean waters. Ocean Policy Res. 2015;30:165-88.

Son WJ, Lee BK, Cho IS. A study on ship safety distance between AIS based ships route and offshore wind farm. In: Proceedings of the Korean Institute of Navigation and Port Research Conference; 2019; Jeju, Korea. p. 79-81.

Southall BL, Bowles AE, Ellison WT, Finneran JJ, Gentry RL, Greene CR Jr, et al. Marine mammal noise-exposure criteria: initial scientific recommendations. Bioacoustics. 2008;17:273-5. 